\title{
Not all synesthetes are alike: spatial vs. visual dimensions of sequence-space synesthesia
}

\author{
Clare N. Jonas ${ }^{1 *}$ and Mark C. Price ${ }^{2}$ \\ 'School of Psychology, University of East London, London, UK \\ ${ }^{2}$ Faculty of Psychology, University of Bergen, Bergen, Norway \\ *Correspondence: c.n.jonas@uel.ac.uk
}

Edited by:

Roberta Sellaro, Leiden University, Netherlands

Reviewed by:

Olesya Blazhenkova, Sabanci University, Turkey

Keywords: synesthesia, spatial imagery, visual imagery, mental imagery, prevalence

\section{THE VARIABILITY OF \\ SEQUENCE-SPACE SYNESTHESIA}

Sequence-space synesthesia (SSS) is a common condition in which ordinal sequences such as months, numbers or the letters of the alphabet are perceived to occupy spatial locations in the mind's eye or peripersonal or extrapersonal space (e.g., Price and Mentzoni, 2008; Jonas and Jarick, 2013). For example, thinking about a month may elicit the visuospatial impression of a circular arrangement of the months, or hearing a numeral may elicit a specifically shaped number line. These "spatial forms" are typically thought to be consistent over time within an individual (e.g., Smilek et al., 2007), though they can actually evolve (Price and Pearson, 2013; Gould et al., 2014; Price, 2014; see also Simner, 2012; Meier et al., 2014). They are also idiosyncratic, with synesthetes reporting many different shapes of varying complexity (Galton, 1880; Phillips, 1897) that are experienced outside the body (i.e., projected) or in the mind's eye (i.e., associated; Dixon et al., 2004; Smilek et al., 2007; Ward et al., 2007).

SSS can vary along several dimensions, including the projector-associator distinction, automaticity, visual salience, and type of spatial transformation that can be applied to the spatial form (e.g., Price, 2013; Price and Mattingley, 2013). Since SSS could be considered a variety of visuospatial mental imagery, these individual differences may reflect known fractionation of imagery processes and skills (Price, 2013; Price and Pearson, 2013). However, a thorough and empirically grounded taxonomy for individual differences in SSS is missing (Price, 2014). We explore here a possible systematization for one area of these individual differences - the visual and spatial qualities of SSS. We further suggest this can help to classify synesthetes as experimental participants and perhaps explain some inconsistencies in published data.

\section{CLASSIFYING THE VISUOSPATIAL NATURE OF SEQUENCE-SPACE SYNESTHESIA}

The visuospatial experiences of SSS are often referred to as spatial forms. For some synesthetes the forms are indeed a felt impression of spatial locations with minimal visual content. Others, however, report having a visual impression of their forms (Eagleman, 2009; Price, 2013); examples of detailed visual content such as texture, color, written text, and, associated visual images are often found in reports on SSS (e.g., Seron et al., 1992; Jonas et al., 2011; Gould et al., 2014; Price, 2014). It has been speculated (Price, 2013; Price and Pearson, 2013) that this variation reflects the distinction, from research on non-synesthetic imagery, between (1) spatial imagery of explicit spatial relationships that may be detailed and complex, which at its most sophisticated level takes the form of a spatial map with flexible viewpoints, (2) visual imagery that depicts visual appearance and more holistically represents visual surface properties. These complementary aspects of visuospatial imagery are tapped by different behavioral tests, are associated with separable working memory modules, and are implemented by separable neural networks, with spatial vs. visual components reflecting the dorsal vs. ventral streams of visual processing (Hegarty, 2004; Mazard et al., 2004; Kosslyn et al., 2007).

Here we suggest refining the visual vs. spatial imagery distinction as previously applied to SSS. It may be too simplistic to characterize synesthetes' forms as being either visual or spatial (as Price, 2014, suggested). Instead, we should characterize an individual's SSS along both visual and spatial dimensions. If these are orthogonal at the level of the individual, the synesthete may be independently high or low on each dimension.

Visual vs. spatial dimensions would respectively reflect an emphasis of ventral vs. dorsal stream activation in mediating synaesthetic imagery. This is consistent both with the view that SSS is continuous with normal visuospatial imagery (Price and Mattingley, 2013; Price and Pearson, 2013), and with proposals that SSS derives from functionally or structurally abnormal neural connectivity. Eagleman's (2009) suggestion that SSS is mediated by unusual connectivity to ventral stream representations could account for the visual aspects of SSS that he emphasizes. Suggestions that SSS derives from dorsal stream connectivity between spatial and magnitude representation in parietal cortex (e.g., Tang et al., 2008; Hubbard et al., 2011), could by contrast be more relevant for spatial aspects.

\section{SPATIAL DIMENSION}

This dimension characterizes the extent to which spatial forms can be construed as spatial models where people have explicit 
introspective access to the relative positions of sequence members. A synesthete low on this dimension has a form viewed consistently from the same vantage point, with low spatial resolution. A synesthete high on this dimension has a more explicit spatial model which will facilitate spatial transformations and allow forms to be seen from multiple viewpoints (Burgess, 2006), even if they have a typical viewpoint. The spatial representation may have vague sketch-like visual qualities but, as spatial sensation is created multi-modally, it could also occur without them.

One example of this distinction is seen in SSS for months, where some synesthetes report that their form is always located in the same space, while others report movement of the calendar or the self in relation to it over the year (Smilek et al., 2007). A more unusual example of spatial transformation comes from a synesthete (Jarick et al., 2009, 2010, 2013) who views her month form from different vantage points depending on whether she hears or reads the name of a month.

Different types of sequence may encourage different degrees of introspective access, along with different degrees and varieties of spatial transformation. For example, the first author (who has SSS) finds that examining spatial forms (e.g., her form for exam grades) improves introspective access. In terms of transformation, whereas SSS for months is often reported to move spontaneously with the passage of time, transformation of number forms (containing potentially infinite sequence members) typically involves more effortful "focus" or "zooming in" (Seron et al., 1992). By contrast, SSS for the alphabet (e.g., Jonas et al., 2011) may make low demands on spatial transformation because the alphabet does not change over time and is constrained enough to be seen from one viewpoint.

\section{VISUAL DIMENSION}

For synesthetes with low visual experience, spatial forms will seem to occupy space, but lack depictive visual quality. By contrast, synesthetes with high visual experience "see" their spatial form in visual detail from a particular viewpoint in their mind's eye, or in peripersonal or extrapersonal space (converging respectively with Ward et al. (2007), classification of graphemecolor synesthetes as see-associators, experiencing colors in their minds' eye, or projectors, whose graphemes have colors "out there" in the world).

\section{ORTHOGONAL DIMENSIONS}

The relation between these proposed spatial and visual dimensions of SSS experience remains to be empirically established. However, taking SSS for months as an example, we can envisage a $2 \times 2$ matrix containing the four extreme combinations of high and low spatial and visual characteristics (Table 1). Gradations between these extremes are also possible.

\section{USING THE VISUAL/SPATIAL CLASSIFICATION TO EXPLAIN CONFLICTING FINDINGS PREVALENCE OF SSS}

Given the assumption that SSS is consistent over at least short periods of time, a common method of verifying SSS is to quantify this consistency because, even with a very good memory, a nonsynesthete would be unlikely to mimic the consistency arising from perceiving a spatial form.

The least stringent consistency test, used by Sagiv et al. (2006, $N=311)$, is to ask participants to draw their spatial associations twice, weeks or months apart, and to assess whether the drawings match. Sagiv et al. estimated prevalences of $20 \%$ for SSS involving time (days and/or months), 12\% for SSS involving numbers, and $15 \%$ for SSS involving the alphabet (totaling 29\% prevalence for any of the three types).

More stringent methods have since been developed, including Brang et al. (2010) within-session technique of asking participants with SSS for months to "project" their form onto a computer screen and indicate month location with mouse-clicks (each month was tested five times). This yielded a prevalence estimate of $2.2 \%$, defined as the proportion of participants $(N=183)$ whose consistency was $>1.96 S D$ above the mean. This estimate is not directly comparable with Sagiv et al.'s estimate of $20 \%$ Brang et al. focused on months while Sagiv et al. made no distinction between days and months. Additionally, Brang et al.'s classification of participants as synesthetes if they showed outlier consistency is far more stringent than the criterion adopted by Sagiv et al. and as Brang et al. admitted, may have been overly conservative. Other studies have obtained estimates intermediate

Table 1 | Characterisation of SSS for calendar months that fall on low vs. high ends of orthogonal visual and spatial dimensions.

\begin{tabular}{|c|c|c|c|}
\hline & & \multicolumn{2}{|c|}{ Graded SPATIAL dimension } \\
\hline & & LOW & HIGH \\
\hline $\begin{array}{l}\frac{0}{0} \\
\frac{0}{0} \\
\frac{5}{0} \\
\frac{5}{0}\end{array}$ & 이 & $\begin{array}{l}\text { There is a vague non-visual feeling of } \\
\text { approximate fixed positions for months } \\
\text { (i.e., little depictive visual quality, little } \\
\text { detailed introspective access and/or } \\
\text { transformational flexibility as a spatial } \\
\text { model). }\end{array}$ & $\begin{array}{l}\text { There is a precise but non-visual knowledge of month positions } \\
\text { with the possibility of flexible transformation of viewpoint. }\end{array}$ \\
\hline
\end{tabular}

The spatial layout of the month form is vividly visualized in a holistic manner, from a fixed perspective, and relative spatial locations need to be inspected effortfully in the visual image rather than being known directly.

\begin{abstract}
There is precise knowledge of month positions, relative to each other or to the body of the viewer, and the spatial model of the months can be rotated, and/or viewed from different perspectives, and or traveled in mentally. Different viewpoints of the spatial form are instantiated as vivid visual images with depictive quality of surface characteristics of the form.
\end{abstract}


between these extremes (e.g., Chun and Hupé, 2013), but here we wish to raise the point that an additional cause of widely varying prevalence estimates may be that different methods selectively target different sub-types of spatial form.

For example, "projecting" one's month calendar onto a screen is likely easier for synesthetes high on the spatial dimension, who can view and rescale their calendar. Other synesthetes could be missed, and Brang et al. notably reported that some kind of mental layout for the months was verbally reported for $44 \%$ of their sample. Sagiv et al.'s drawing method may, by contrast, be easier for synesthetes high on the visual dimension. If highly visual SSS were more common than highly spatial SSS, then it is perhaps unsurprising that visually-based prevalence estimates such as that of Sagiv et al. are higher than spatially-based estimates such as that of Brang et al. It is indeed likely that visual SSS is most common: Strong experience of visual imagery seems more prevalent than strong spatial imagery in the general population (Chabris et al., 2006; Blazhenkova and Kozhevnikov, 2009), and several studies have found that samples of people with SSS-who were more neutrally recruited via verbal reportshow elevated self-report scores for visual, but not spatial, imagery (Price, 2009; Rizza and Price, 2012; Meier and Rothen, 2013).

\section{BEHAVIORAL MEASURES OF MENTAL IMAGERY IN PEOPLE WITH SSS}

Although high self-reported visual imagery scores among synesthetes seem replicable, results from behavioral tests of visuospatial imagery have been mixed (for further discussion see Simner, 2013; Price, 2013). Simner et al. (2009) found increased accuracy in synesthetes with time-related forms compared to controls on Benton's test of 3D praxis, VOSP progressive silhouettes, and 3D mental rotation. Brang et al. (2013) reported increased accuracy in time-space synesthetes performing $2 \mathrm{D}$ mental rotation of letters compared to non-synesthetes. However, Rizza and Price (2012) reported that time-space synesthetes performed no better than non-synesthetes on 3D imagery tests of paper folding and mental rotation.
To distinguish between rival explanations for these discrepancies (e.g., demand characteristics; lack of power; non-equivalence of tasks in different studies), further replication is needed with larger sample sizes and multiple behavioral imagery tests. However, we suggest that individual differences in synesthetes along spatial and visual dimensions could contribute to varied findings. For example, synaesthetes who are low on our visual dimension may not perform 3D mental rotation unusually well because this test correlates with self-reported spatial rather than visual imagery (e.g., Blazhenkova and Kozhevnikov, 2010). This may have been the case for the study by Rizza and Price (2012). If so-called "spatial" forms are often visual in nature (Eagleman, 2009; Price, 2013), and if such forms are more common than highly spatial variants, then it is plausible that small, randomlyselected SSS samples will contain few highly spatial participants. However, if the recruitment method favors spatial SSS, then a synesthete advantage for mental rotation may be obtained because such participants are by definition good at spatial transformation.

\section{CONCLUSION}

We have suggested that characterizing SSS in terms of its orthogonal spatial vs. visual properties may capture some of the ways in which this experience varies between individuals. We have also speculated that failure to make this type of distinction between individual synesthetes may contribute to widely differing prevalence estimates and to divergent claims about the visuospatial skills associated with SSS. Further defining and refining empirical methods for classifying participants along spatial and visual dimensions would provide a helpful way to screen participants in future studies addressing the prevalence, behavioral correlates and neurocognitive basis of this condition.

\section{REFERENCES}

Blazhenkova, O., and Kozhevnikov, M. (2009). The new object-spatial-verbal cognitive style model: theory and measurement. Appl. Cogn. Psychol. 23, 638-663. doi: 10.1002/acp.1473

Blazhenkova, O., and Kozhevnikov, M. (2010). Visual-object ability: a new dimension of nonverbal intelligence. Cognition 117, 276-301. doi: 10.1016/j.cognition.2010.08.021
Brang, D., Miller, L. E., McQuire, M., Ramachandran, V. S., and Coulson, S. (2013). Enhanced mental rotation ability in time-space synesthesia. Cogn. Process. 14, 429-434. doi: 10.1007/s10339-0130561-5

Brang, D., Teuscher, U., Ramachandran, V. S., and Coulson, S. (2010). Temporal sequences, synesthetic mappings, and cultural biases: the geography of time. Conscious. Cogn. 19, 311-320. doi: 10.1016/j.concog.2010.01.003

Burgess, N. (2006). Spatial memory: how egocentric and allocentric combine. Trends Cogn. Sci. 10, 551-557. doi: 10.1016/j.tics.2006.10.005

Chabris, C. F., Jerde, T. L., Woolley, A. W., Hackman, J. R., and Kosslyn, S. M. (2006). "Spatial and object visualization cognitive styles: validation studies in 3800 individuals," in Technical Report \#2, Project on Human Cognition and Collective Performance (Cambridge, MA: Department of Psychology, Harvard University).

Chun, C. A., and Hupé, J. M. (2013). Mirror-touch and ticker tape experiences in synesthesia. Front. Psychol. 8:776. doi: 10.3389/fpsyg.2013.00776

Dixon, M. J., Smilek, D., and Merikle, P. M. (2004). Not all synaesthetes are created equal: projector versus associator synaesthetes. Cogn. Affect. Behav. Neurosci. 4, 335-343. doi: 10.3758/CABN. 4.3.335

Eagleman, D. M. (2009). The objectification of overlearned sequences: a new view of spatial sequence synesthesia. Cortex 45, 1266-1277. doi: 10.1016/j.cortex.2009.06.012

Galton, F. (1880). Visualised numerals. Nature 21, 252-256. doi: 10.1038/021252a0

Gould, C., Froese, T., Barrett, A. B., Ward, J., and Seth, A. K. (2014). An extended case study on the phenomenology of spatial form synaesthesia. Front. Hum. Neurosci. 8:433. doi: 10.3389/fnhum.2014.00433

Hegarty, M. (2004). Mechanical reasoning by mental simulation. Trends Cogn. Sci. 8, 280-285. doi: 10.1016/j.tics.2004.04.001

Hubbard, E. M., Brang, D., and Ramachandran, V. S. (2011). The cross-activation theory at 10. J. Neuropsychol. 5, 152-177. doi: 10.1111/j.17486653.2011.02014.x

Jarick, M., Dixon, M. J., Stewart, M. T., Maxwell, E. C., and Smilek, D. (2009). A different outlook on time: visual and auditory month names elicit different mental vantage points for a timespace synaesthete. Cortex 45, 1217-1228. doi: 10.1016/j.cortex.2009.05.014

Jarick, M., Hawco, C., Ferretti, T., and Dixon, M. (2010). Electrophysiological evidence supporting the automaticity of synaesthetic number-forms. J. Vis. 10, 875-875. doi: 10.1167/10.7.875

Jarick, M., Stewart, M. T., Smilek, D., and Dixon, M. J. (2013). Do you see what I hear? Vantage point preference and visual dominance in a time-space synaesthete. Front. Psychol. 4:695. doi: 10.3389/fpsyg.2013.00695

Jonas, C., and Jarick, M. (2013). "Synaesthesia, sequences and space," in Oxford Handbook of Synaesthesia, eds J. Simner and E. M. Hubbard (Oxford: Oxford University Press), 123-149. doi: 10.1093/oxfordhb/9780199603329.013.0007

Jonas, C. N., Taylor, A. J., Hutton, S., Weiss, P. H., and Ward, J. (2011). Visuo-spatial representations of the alphabet in synaesthetes and non-synaesthetes. 
J. Neuropsychol. 5, 302-322. doi: 10.1111/j.17486653.2011.02010.x

Kosslyn, S. M., Shephard, J. M., and Thompson, W. L. (2007). "Spatial processing during mental imagery: a neurofunctional theory," in Spatial Processing in Navigation, Imagery and Perception, eds F. Mast and L. Jäncke (New York, NY: Springer), 1-15.

Mazard, A., Tzourio-Mazoyer, N., Crivello, F., Mazoyer, B., and Mellet, E. (2004). A PET meta-analysis of object and spatial mental imagery. Eur. J. Cogn. Psychol. 16, 673-695. doi: 10.1080/09541440340000484

Meier, B., and Rothen, N. (2013). Graphemecolour synaesthesia is associated with a distinct cognitive style. Front. Psychol. 4:632 doi: 10.3389/fpsyg.2013.00632

Meier, B., Rothen, N., and Walter, S. (2014). Developmental aspects of synaesthesia across the adult lifespan. Front. Hum. Neurosci. 8:129. doi: 10.3389/fnhum.2014.00129

Phillips, D. E. (1897). Genesis of number-forms. Am. J. Psychol. 8, 506-527. doi: 10.2307/1411774

Price, M. C. (2009). Spatial forms and mental imagery. Cortex 45, 1229-1245. doi: 10.1016/j.cortex.2009.06.013

Price, M. C. (2013). "Synaesthesia, imagery, and performance," in Oxford Handbook of Synaesthesia, eds J. Simner and E. M. Hubbard (Oxford: Oxford University Press), 728-757. doi: 10.1093/oxfordhb/9780199603329.013.0037

Price, M. C. (2014). Insights from introspection: a commentary on Gould et al. (2014), "An extended case study on the phenomenology of spatial form synaesthesia." Front. Hum. Neurosci. 8:439. doi: 10.3389/fnhum.2014.00439
Price, M. C., and Mattingley, J. B. (2013). Automaticity in sequence-space synaesthesia: a critical appraisal of the evidence. Cortex 49, 1165-1186. doi: 10.1016/j.cortex.2012.10.013

Price, M. C., and Mentzoni, R. A. (2008). Where is January? The month-SNARC effect in sequenceform synaesthetes. Cortex 44, 890-907. doi: 10.1016/j.cortex.2006.10.003

Price, M. C., and Pearson, D. G. (2013). Toward a visuospatial developmental account of sequencespace synesthesia. Front. Hum. Neurosci. 7:689. doi: 10.3389/fnhum.2013.00689

Rizza, A., and Price, M. C. (2012). Do sequencespace synaesthetes have better spatial imagery skills? Maybe not. Cogn. Process. 13, 299-303. doi: 10.1007/s10339-012-0459-7

Sagiv, N., Simner, J., Collins, J., Butterworth, B., and Ward, J. (2006). What is the relationship between synaesthesia and visuo-spatial number forms? Cognition 101, 114-128. doi: 10.1016/j.cognition.2005.09.004

Seron, X., Pesenti, M., Noël, M. P., Deloche, G., and Cornet, J. A. (1992). Images of numbers, or "When 98 is upper left and 6 sky blue." Cognition 44, 159-196. doi: 10.1016/0010-0277(92) 90053-K

Simner, J. (2012). Defining synaesthesia. Br. J. Psychol. 103, 1-15. doi: 10.1348/000712610X528305

Simner, J. (2013). Why are there different types of synesthete? Front. Psychol. 4:558. doi: 10.3389/fpsyg.2013.00558

Simner, J., Mayo, N., and Spiller, M. J. (2009). A foundation for savantism? Visuo-spatial synaesthetes present with cognitive benefits. Cortex 45, 1246-1260. doi: 10.1016/j.cortex.2009. 07.007
Smilek, D., Callejas, A., Dixon, M. J., and Merikle, P. M. (2007). Ovals of time: time-space associations in synaesthesia. Conscious. Cogn. 16, 507-519. doi: 10.1016/j.concog.2006.06.013

Tang, J., Ward, J., and Butterworth, B. (2008). Number forms in the brain. J. Cogn. Neurosci. 20, 1547-1556. doi: $10.1162 /$ jocn.2008. 20120

Ward, J., Li, R., Salih, S., and Sagiv, N. (2007). Varieties of grapheme-colour synaesthesia: a new theory of phenomenological and behavioural differences. Conscious. Cogn. 16, 913-931. doi: 10.1016/j.concog.2006.09.012

Conflict of Interest Statement: The authors declare that the research was conducted in the absence of any commercial or financial relationships that could be construed as a potential conflict of interest.

Received: 10 July 2014; accepted: 26 September 2014; published online: 30 October 2014.

Citation: Jonas CN and Price MC (2014) Not all synesthetes are alike: spatial vs. visual dimensions of sequence-space synesthesia. Front. Psychol. 5:1171. doi: 10.3389/fpsyg.2014.01171

This article was submitted to Cognition, a section of the journal Frontiers in Psychology.

Copyright (c) 2014 Jonas and Price. This is an openaccess article distributed under the terms of the Creative Commons Attribution License (CC BY). The use, distribution or reproduction in other forums is permitted, provided the original author(s) or licensor are credited and that the original publication in this journal is cited, in accordance with accepted academic practice. No use, distribution or reproduction is permitted which does not comply with these terms. 